\title{
ESTUDO DE AMBIENTE CONSTRUÍDO COM MATERIAIS RECICLÁVEIS
}

Camila Pires Cremasco' ${ }^{1}$ Daniel dos Santos Viais Neto' ${ }^{1}$ Marcelo Albieri Melo², Lucas Albieri Figueiredo ${ }^{2}$, Gabriel Albieri Peres ${ }^{3}$

${ }^{1}$ Docentes da Faculdade de Tecnologia de Presidente Prudente - FATEC. ${ }^{2}$ Tecnólogo em Agronegócio pela Faculdade de Tecnologia de Presidente Prudente - FATEC. ${ }^{3}$ Engenheiro Ambiental pela Universidade Paulista Julio de Mesquita Filho-UNESP de Presidente Prudente.

\section{RESUMO}

A sustentabilidade e a melhoria da qualidade de vida da sociedade como um todo tem sido tema de discussão de importantes centros de pesquisa em diversas áreas. A presente proposta tem como objetivo relatar alguns resultados sobre a construção de um ambiente com materiais recicláveis na FATEC de Presidente Prudente onde o principal material a são as garrafas de PET e elaborar um manual contendo todas etapas da construção deste ambiente. Pretende-se investigar todo processo da construção, desde o orçamento até etapas finais de acabamento. $O$ projeto beneficia a sustentabilidade e o meio ambiente.

Palavras-chave: sustentabilidade, conforto térmico, fundação, manual, baixo custo.

\section{INTRODUÇÃO E OBJETIVO}

O objetivo deste trabalho foi relatar o inicio da construção de um espaço piloto na Fatec de Presidente Prudente com materiais recicláveis onde o principal material a ser utilizado são as garrafas de PET's. Este ambiente será a base para se realizar pesquisas sobre acústica e conforto térmico utilizando à lógica fuzzy. Atualmente este projeto encontra-se em andamento, o primeiro resultado a ser apresentado neste artigo, avalia o método de construção e a determinação do material para a construção e o auxilio dos interessados em tal tecnologia.

O desenvolvimento tecnológico crescente associado a profundas mudanças no modo de vida contemporâneo tem gerado volumes de rejeitos cada vez maiores, os quais poderão se tornar um problema para a humanidade se não forem tomadas medidas para reduzir as quantidades encaminhadas diariamente para os lixões ou aterros sanitários. Como conseqüência destes eventos surgiram às leis ambientais e a sociedade como um todo passou por um processo de conscientização, levando as empresas e a própria sociedade a se preocuparem com a transformação de seus rejeitos em resíduos (OLIVEIRA; CASTRO, 2002). Entre os diversos danos causados ao meio ambiente, pode-se destacar o resíduo plástico, que possui um tempo de degradação elevado e se queimados liberam gases tóxicos (ZANIN; MANCINI, 2004). Segundo Wiebeck e Harada (2005), a reciclagem é uma alternativa para reduzir o impacto ambiental da matéria-prima plástica descartada. Outras maneiras de aproveitamento de materiais recicláveis 
são em construções de ambientes utilizando garrafas pet em substituição de tijolos. Acredita-se que a construção com garrafas de pet pode reduzir o custo da obra em $2 / 3$ do valor. A primeira casa brasileira construída com garrafas pet foi em Tarumirim - MG no ano de 2010, possui $30 \mathrm{~m} 2$ e foi utilizada aproximadamente 10 mil garrafas de pets (ABIPET, 2012). Ao se construir este tipo de ambiente deve-se preocupar com o conforto térmico que segundo a ABNT (2005), é a satisfação psicofisiológica de um indivíduo com as condições térmicas do ambiente. Os estudos de conforto térmico visam analisar e estabelecer as condições necessárias para a avaliação e concepção de um ambiente térmico adequado às atividades e ocupação humanas, bem como estabelecer métodos e princípios para uma detalhada análise térmica de um ambiente (LAMBERTS, 2012).

\section{METODOLOGIA}

O projeto esta sendo desenvolvido na Fatec de Presidente Prudente localizada na Rua Terezina, $n^{\circ}$ 75, Vila Paulo Roberto, Presidente Prudente - SP. Além disso, a Casa Pet será construída dentro das dependências da Fatec, no espaço demarcado pelos alunos, ao lado das estufas como mostra a Figura 1. E a fundação é a base da implantação proposta neste trabalho sendo o primeiro resultado do projeto.

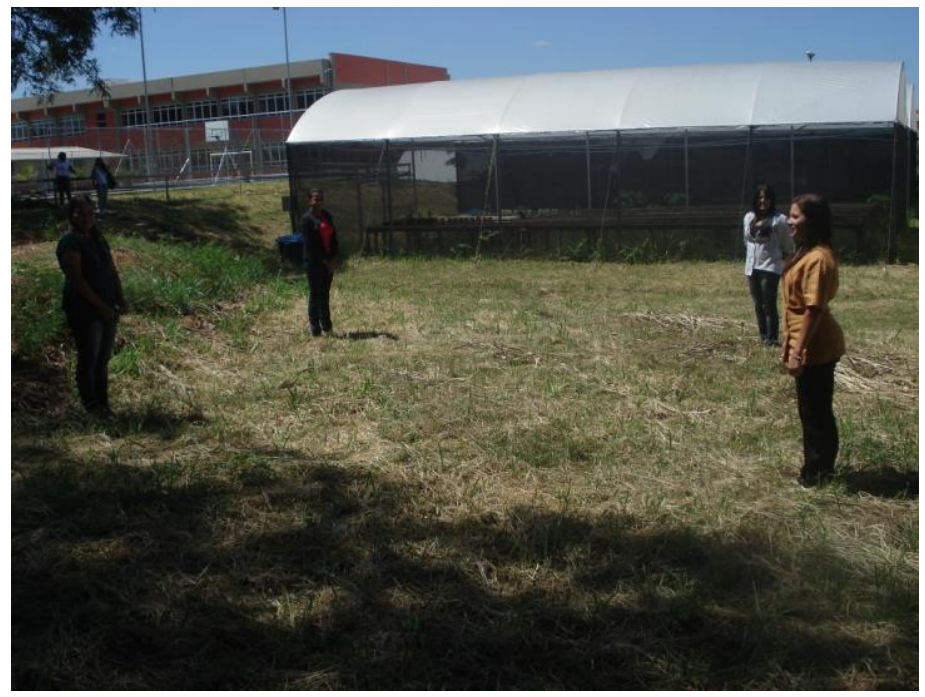

Figura 1. Foto do local de construção da Casa Pet.

A Casa Pet ocupará um espaço de $24 \mathrm{~m}^{2}$, sendo $16 \mathrm{~m}^{2}$ de sala e $8 \mathrm{~m}^{2}$ de área de serviço como mostra a planta-baixa (Figura 5). Entre a sala e a área de área de serviço será colocada uma janela e uma porta. Além disso, será instalado um encanamento externo para acomodação de uma pia na área de serviço. 


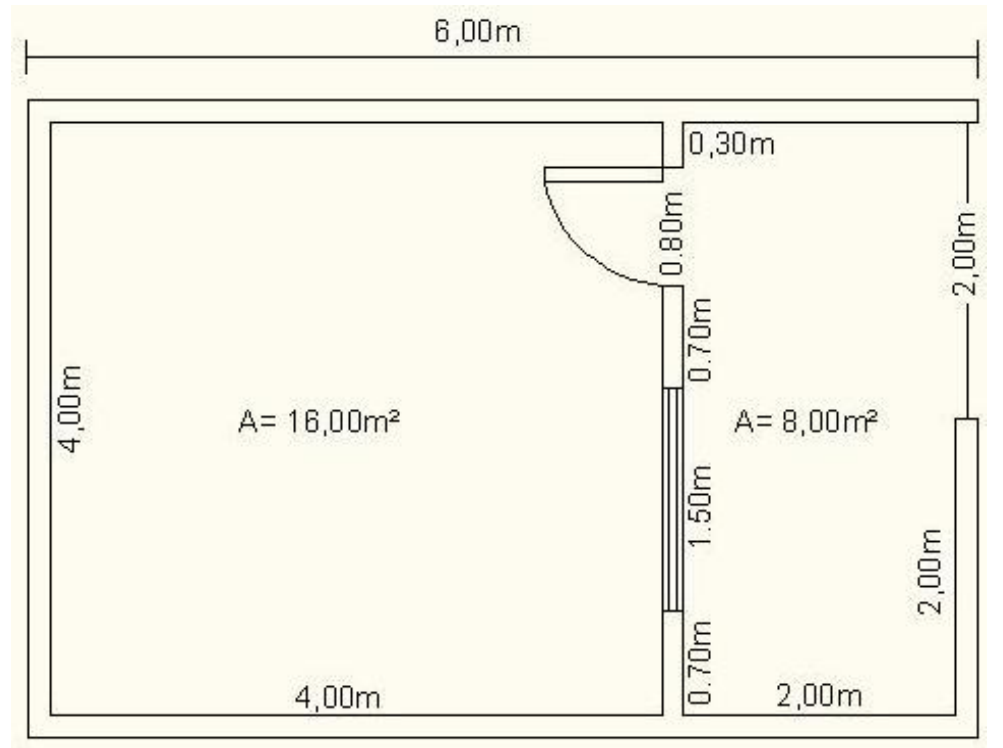

Figura 2. Planta-baixa da Casa Pet.

Para a elaboração dos relatos relacionados aos métodos e divulgação do "Projeto Casa Pet" foram elaboradas planilhas de custo de todos os materiais necessários para a construção deste ambiente. Para a fundação (primeira etapa do projeto) foram adquiridos tais materiais e realizados testes no preenchimento das garrafas levando em consideração a resistência e o tempo necessário para encher as garrafas com areia, barro e solo cimento (mistura de barro e $10 \%$ de cimento).

\section{RESULTADOS}

O inicio deste projeto ocorreu em março com a premiação do projeto no Instituto $3 \mathrm{M}$ em Sumaré. As figuras 1, 2 e 3 ilustram a premiação no valor de $\mathrm{R} \$ 30.000$ reais. A construção da Casa Pet esta em andamento e as Figuras 3 ilustram o inicio da obra e as etapas de desenvolvimento até o momento. Em cada etapa esta se construindo um manual para que interessados possam replicá-la.

Até o momento a fundação esta pronta, foram usados $10 \mathrm{~kg}$ de cimento, $1 \mathrm{~m} 3$ de pedra 1/8(fina para concreto), $3 \mathrm{~m} 3$ de areia fina e 600 garrafas pet que foram preenchidas com areia, terra e barro. Também houve a colaboração do grupo dos escoteiros para preencher as 600 garrafas em uma ação que ocorreu na Fatec de Presidente Prudente.

A coleta de garrafas pet contou com a colaboração de toda a população na região da Fatec de Presidente Prudente e alunos dos cursos. Uma contribuição especial foi realizada pelo grupo dos escoteiros. 

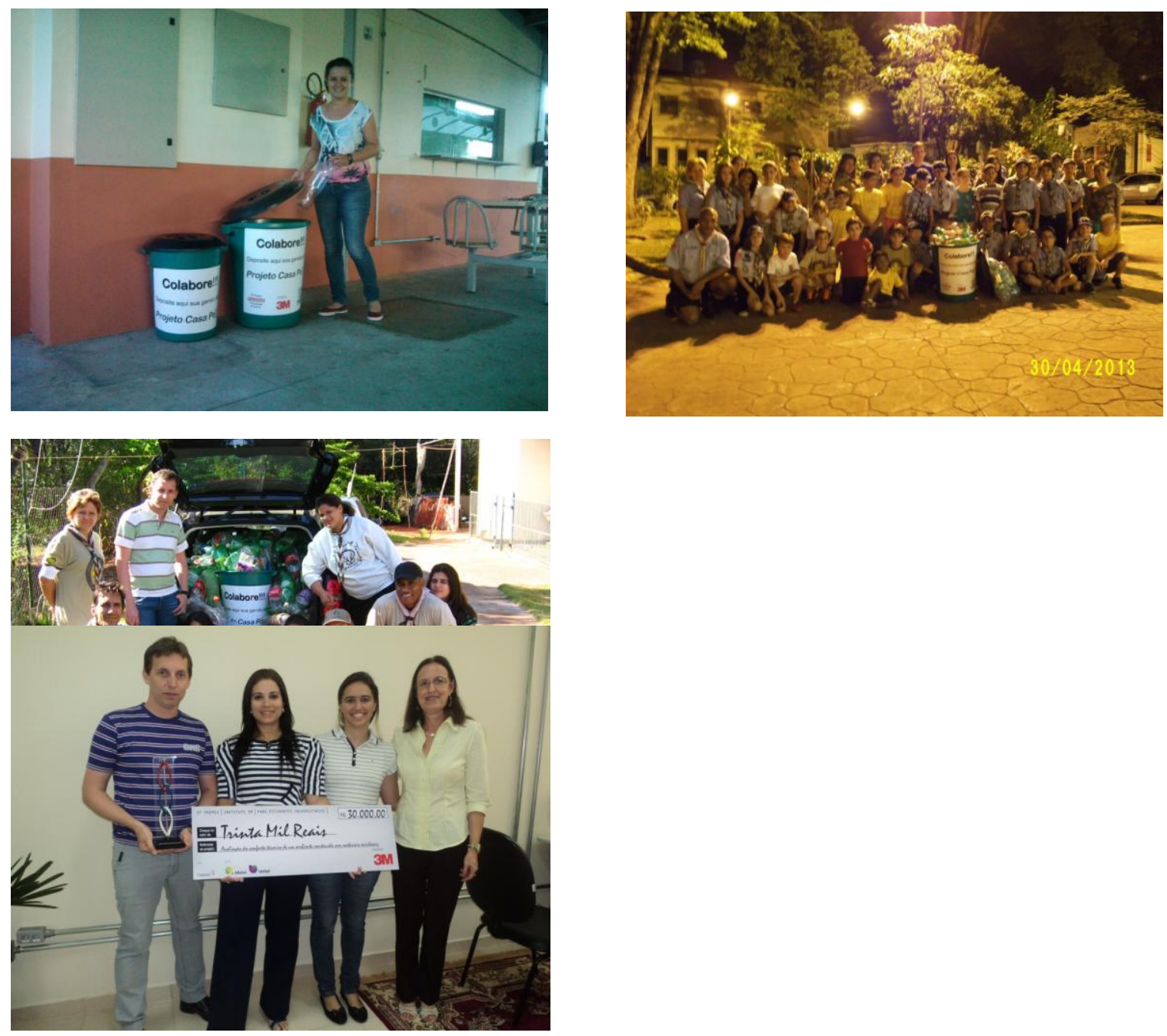

Figura 4. Premiação e inicio das coletas.

A primeira etapa da construção da é a fundação, neste projeto o alicerce deve ser mais forte já o projeto ainda visa a construção de um telhado verde. Portanto o custo desta primeira etapa foi mais alto do que o esperado. Foram elaboradas planilhas de custo para que ao fim do projeto estas sejam utilizadas na elaboração de uma manual. A Figura 5 ilustra a construção da fundação.
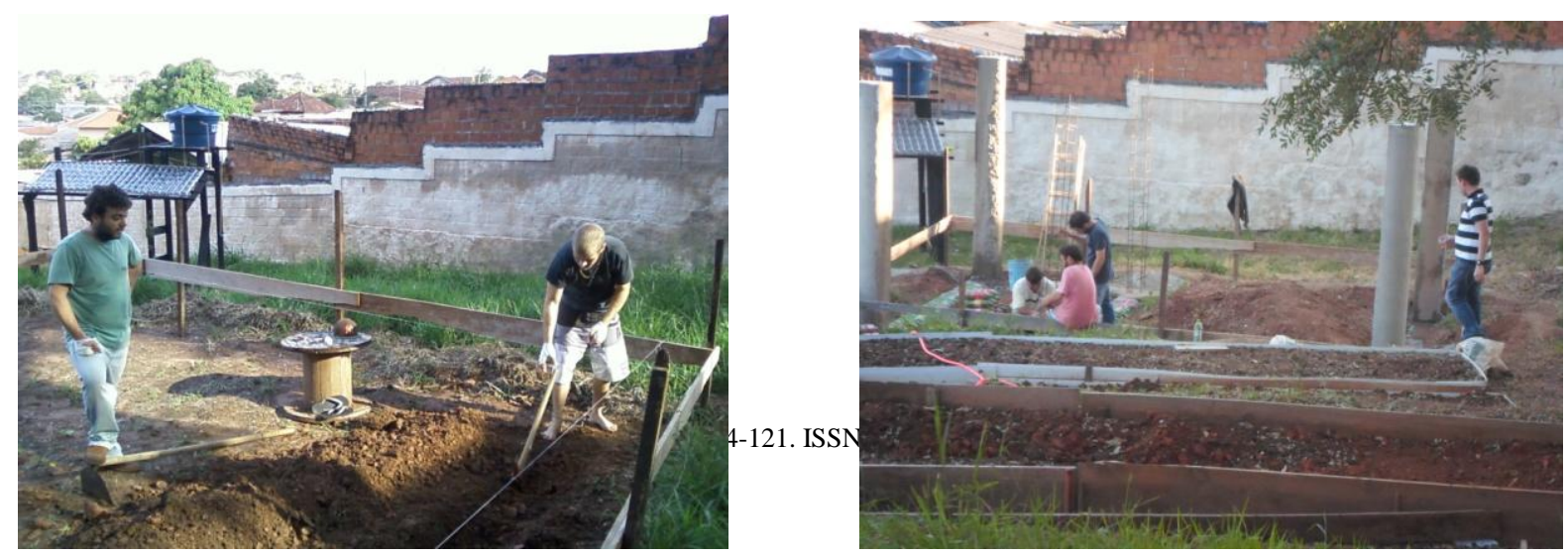

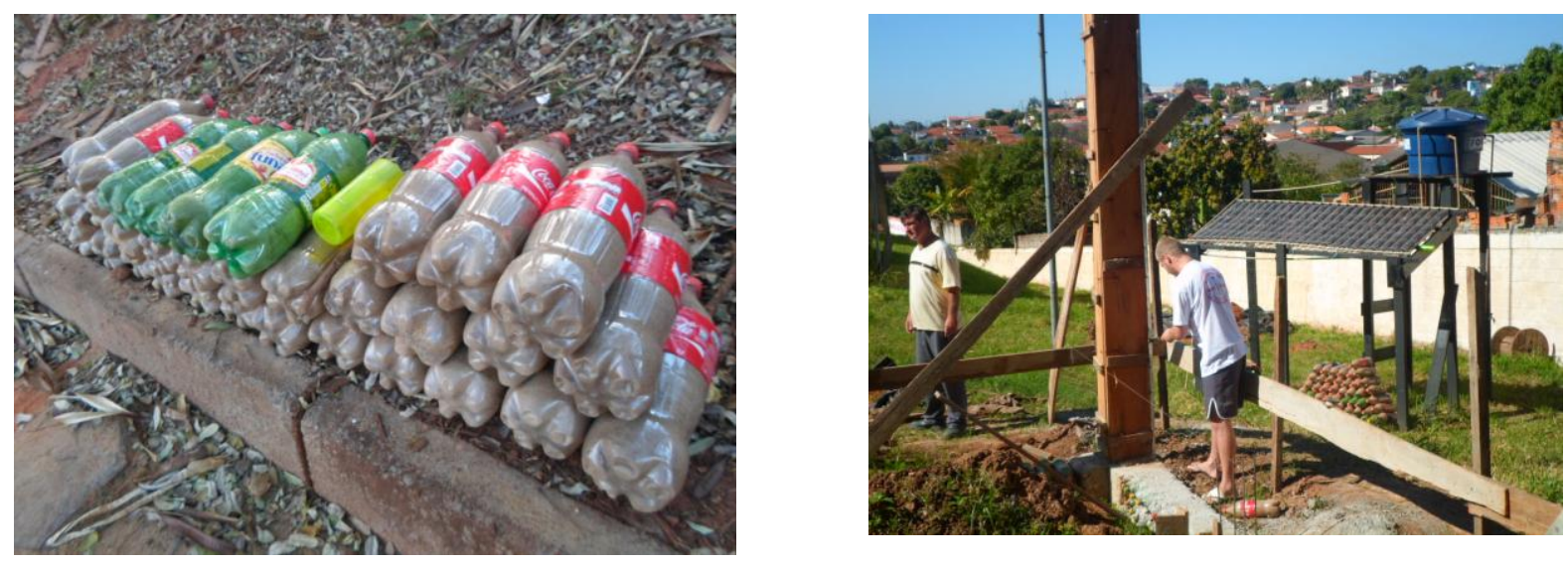

Figura 5. Construção da casa (etapa fundação).

A Tabela 1, apresenta parte do material necessário para a construção do ambiente determinada por uma mestre de obras.

Tabela 1. Orçamento financeiro do desenvolvimento do experimento.

\begin{tabular}{|c|c|c|c|}
\hline Itens de Dispêndio & $\begin{array}{l}\text { Quan } \\
\text { tidade }\end{array}$ & $\begin{array}{l}\text { Pre } \\
\text { ço } \\
\text { unitário }\end{array}$ & $\begin{array}{l}\text { Preço } \\
\text { total }\end{array}$ \\
\hline \multicolumn{4}{|l|}{ Capital } \\
\hline ESTRUTURA & & & \\
\hline Cimento (saco 50 kg) & 25 & $\begin{array}{r}25 \\
00\end{array}$ & 625,0 \\
\hline Cal (saco $20 \mathrm{~kg}$ ) & 10 & $\begin{array}{r}8,5 \\
0\end{array}$ & 85,00 \\
\hline Areia lavada $\left(\mathrm{m}^{3}\right)$ & 05 & $\begin{array}{r}84, \\
36 \\
\end{array}$ & $\begin{array}{r}421,8 \\
0 \\
\end{array}$ \\
\hline Areia fina $\left(\mathrm{m}^{3}\right)$ & 03 & $\begin{array}{r}56, \\
00\end{array}$ & $\begin{array}{r}168,0 \\
0\end{array}$ \\
\hline Pedra $\left(\mathrm{m}^{3}\right)$ & 03 & $\begin{array}{r}89 \\
54 \\
\end{array}$ & $\begin{array}{r}268,6 \\
2 \\
\end{array}$ \\
\hline Ferro 3/8 (barra 12 m) & 25 & $\begin{array}{r}30 \\
51\end{array}$ & $\begin{array}{r}762,7 \\
5\end{array}$ \\
\hline Ferro 5/16 (barra $12 \mathrm{~m}$ ) & 30 & $\begin{array}{r}20 \\
88\end{array}$ & $\begin{array}{r}626,4 \\
0\end{array}$ \\
\hline Arame cozido (kg) & 10 & $\begin{array}{r}6,6 \\
0\end{array}$ & 66,00 \\
\hline Prego 18/24 (pacote $1 \mathrm{~kg}$ ) & 06 & $\begin{array}{r}6,5 \\
0\end{array}$ & 39,00 \\
\hline
\end{tabular}




\begin{tabular}{|c|c|c|c|}
\hline Tábua de cambará 3 m (unid.) & 15 & $\begin{array}{r}30 \\
00\end{array}$ & $\begin{array}{r}450,0 \\
0\end{array}$ \\
\hline Tábua de cambará 3,5 m (unid.) & 04 & $\begin{array}{r}35 \\
00\end{array}$ & $\begin{array}{r}140,0 \\
0\end{array}$ \\
\hline Tábua de cambará 4 m (unid.) & 08 & $\begin{array}{r}40 \\
00\end{array}$ & $\begin{array}{r}320,0 \\
0\end{array}$ \\
\hline Tábua de cambará 4,5 m (unid.) & 02 & $\begin{array}{r}45, \\
00\end{array}$ & 90,00 \\
\hline \multicolumn{4}{|l|}{ ENCANAMENTO } \\
\hline Sifão (unid.) & 01 & $\begin{array}{r}5,2 \\
5 \\
\end{array}$ & 5,25 \\
\hline Cotovelo 50 (unid.) & 02 & $\begin{array}{r}4,2 \\
1\end{array}$ & 8,42 \\
\hline Cola (unid.) & 01 & $\begin{array}{r}4,2 \\
7 \\
\end{array}$ & 4,27 \\
\hline Cotovelo azul 3/4 (unid.) & 01 & $\begin{array}{r}5,2 \\
1 \\
\end{array}$ & 5,21 \\
\hline Cotovelo marrom $3 / 4$ (unid.) & 02 & $\begin{array}{r}0,6 \\
0 \\
\end{array}$ & 1,20 \\
\hline Cano esgoto 90X50 (unid.) & 01 & $\begin{array}{r}5,2 \\
5 \\
\end{array}$ & 31,50 \\
\hline Cano marrom $3 / 4$ (barra 6 m) & 01 & $\begin{array}{r}2,1 \\
8\end{array}$ & 13,08 \\
\hline
\end{tabular}

\section{CONCLUSÃO}

Espera-se comprovar que o ambiente é uma alternativa viável tanto do ponto de vista econômico e do ponto de vista ambiental.

A elaboração do manual esta em andamento, as planilhas de materiais e custo estão elaboradas e continuamente sendo revisadas, já que durante a construção ocorrem alguns imprevistos. A Casa Pet se tornará um ambiente propício à elaboração de novos projetos. Entre eles podemos citar a instalação de um aquecedor solar cujos estudos estão sendo desenvolvidos no Laboratório de Conforto Térmico e Ambiência (LCTA) da UNESP - Campus Experimental de Tupã, colaborador com projetos da Fatec de Presidente Prudente.

A Casa Pet também será aproveitada como depósito para materiais utilizados nas estufas e se tornará um local para a divulgação dos resultados do projeto.

\section{REFERÊNCIAS}

ABIPET - Associação Brasileira de Indústria do PET. 0 que é PET? Disponível em: <http://www.abipet.org.br/index.html?method=mostrarlnstitucional\&id=81>. Acesso em: 23 mar. 2012. 
ABIPET - Associação Brasileira de Indústria do PET. 70 Censo da reciclagem de PET no Brasil 2010. 2011.

Disponível

em:

<http://www.abipet.org.br/index.html?method=mostrarDownloads\&categoria.id=3>. Acesso em: 23 mar. 2012.

ABNT - NBR 15220-1. Desempenho térmico de edificações. Parte 1: Definições, símbolos e unidades. Rio de Janeiro, 2005.

CORREA, C. B. Telhados verdes: a cobertura ecológica. Conselho em Revista. CREA-RS. Porto Alegre, 2007, n. 34, p. 28.

ECOTELHADO - Soluções em Estrutura Verdes. Ecotelhado. Disponível em: <http://www.ecotelhado.com.br/Por/ecotelhado/default.aspx>. Acesso em: 23 mar. 2012.

FORMIGONI, A.; CAMPOS, I. P. A. Reciclagem de PET no Brasil. In: IV Simpósio de Excelência em Gestão e Tecnologia. Resende, 2007.

GABRIEL FILHO, L. R. A.; CREMASCO, C. P.; GABRIEL, L. R. A. Bioestatística e suas aplicações. Editora Espaço Cultural do Brasil. Adamantina, 2009.

HENEIDE, M. C. A. S. "Cobertura verde". Monografia apresentada ao Curso de Especialização em Construção Civil da Escola de Engenharia UFMG. Belo Horizonte, 2008.

LAMBERTS, R. Conforto térmico e stress térmico. UFSC. Florianópolis, 2012.

MANCINI, S. D.; BEZERRA, M. N.; ZANIN, M. Reciclagem de PET advindo de garrafas de refrigerante pós-consumo. Revista Polímeros: Ciência e Tecnologia, São Carlos, 1998, v. 8, n. 2.

OLIVEIRA, T. M.; CASTRO, P. F. Aproveitamento de rejeito plástico como agregado em concreto asfáltico. In: V Congresso Brasileiro de Engenharia Civil. UFJF. Juiz de Fora, 2002.

PEREIRA, R. C. C.; MACHADO, A. H.; SILVA, G. G. (Re) Conhecendo o PET. Revista Química Nova na Escola, São Paulo, 2002, n.15.

PEIXOTO, M. S. Sistemas dinâmicos e controladores fuzzy: um estudo da dispersão da Morte Súbita dos Citros em São Paulo. Campinas, 2005.

PEDRYCZ, W.; GOMIDE, F. An Introduction to fuzzy sets: analysis and design. MIT Press. Cambridge, 1998.

RIBACIONKA, F. Sistemas computacionais baseados em lógica fuzzy. Dissertação de Mestrado, Universidade Mackenzie - São Paulo - SP. 1999.

SHAW, I. S.; SIMÕES, M. G. Controle e modelagem fuzzy. Editora Edgard Blücher Ltda. São Paulo, 1999.

TOMAZ, P. BMPs - Best Management Practices (Melhoria da qualidade das águas pluviais). São Paulo, 2007. Disponível em: <http://www.pliniotomaz.com.br/downloads/livro01v02bmps.pdf>. Acesso em: 23 mar. 2012. 
Encontro de Ensino, Pesquisa e Extensão, Presidente Prudente, 21 a 24 de outubro, 2013

WIEBECK, H.; HARADA, J. Plásticos de engenharia: Tecnologia e Aplicações. Artliber. São Paulo, 2005.

ZADEH, L. A. Fuzzy sets. Informat control. 1965.

ZANIN, M.; MANCINI, S. D. Resíduos plásticos e reciclagem: aspectos gerais e tecnologia. Edufscar. São Carlos, 2004. 